\title{
Factors Associated with Home Delivery in West Pokot County of Kenya
}

\author{
Jared Otieno Ogolla \\ Department of Public Health, School of Health Sciences, Mount Kenya University, P.O. Box 2591-30100, Eldoret, Kenya \\ Correspondence should be addressed to Jared Otieno Ogolla; jotienoogolla@gmail.com
}

Received 23 July 2014; Revised 8 December 2014; Accepted 24 February 2015

Academic Editor: Gudlavalleti Venkata Murthy

Copyright (c) 2015 Jared Otieno Ogolla. This is an open access article distributed under the Creative Commons Attribution License, which permits unrestricted use, distribution, and reproduction in any medium, provided the original work is properly cited.

\begin{abstract}
Background. This paper sought to estimate the percentage of women who deliver at home in West Pokot County and establish the factors associated with home delivery in the area. Design and Methods. The cross-sectional survey targeted 18,174 households between the months of April and July 2013. Six hundred mothers participated in the study. Association between predictors and the place where the delivery took place was analysed by chi-square test $\left(\chi^{2}\right)$ at $95 \%$ confidence interval. Factors with $P$ value $<0.05$ were considered statistically significant. These factors were entered into multivariate logistic regression model after controlling for confounding to ascertain how each one influenced home delivery. Odds ratio was used to determine the extent of association. Results. Based on the mother's most recent births, 200 (33.3\%) women delivered in a health facility while $400(66.7 \%)$ delivered at home. Factors associated with home delivering were housewives (OR: 4.5, 95\% CI: $2.1-9.5 ; P=0.001$ ) and low socioeconomic status of $10 \mathrm{~km}$ (OR: $0.5,9.5 \%$ CI: 0.3-0.7; $P=0.001)$. Conclusions. The findings of this study provide novel information for stakeholders responsible for maternal and child health in West Pokot County.
\end{abstract}

\section{Introduction}

Pregnancy and childbirth related complications contribute to a significant number of pregnancy and childbirth related deaths and disabilities in the world especially in developing countries [1]. The major causes of these deaths are prolonged/obstructed labour, complications from unsafe abortion, haemorrhage, malaria during pregnancy, anaemia, and sepsis [1-3]. Notably, most of these deaths and disabilities are preventable if women make good use of the available maternal health services [1]. Despite the Government of Kenya (GoK) and other stakeholders' efforts to curb pregnancy related deaths and disabilities, maternal mortality rates (MMRs) have remained soaring high in country [2].

Safe motherhood initiatives such as the provision of free maternity services are still being underutilised by many women in Kenya especially those in poor, rural, and remote settings of the country $[1,3,4]$. This has led to extremely high rates of MMRs in some parts of Kenya [1,3]. One such area is West Pokot County. It is estimated that 565 deaths per 100,000 births occur in West Pokot County alone annually [5]. This is a sharp contrast to the reported national rate of 488 deaths per 100,000 live births [3]. However, County MMR is likely to be an underestimation, considering that there is inadequate community-based maternal mortality data in the area [5].

The high MMR in West Pokot is mainly attributed to obstructed labour, high rate of infibulations (type III), and cephalopelvic disproportion (CPD) due to early marriages [5]. It is estimated that $74 \%$ of women in West Pokot County give birth at home with traditional birth attendants (TBAs) attending most of these deliveries [3-5]. Only $10 \%$ of these women receive postpartum care within 2 days $[1-3,5]$. Since most maternal deaths occur in the first week after birth, this means missed opportunity in terms of recognition and responding to danger signs after delivery.

Safe motherhood interventions are thus crucial in reducing maternal deaths and pregnancy associated morbidity in the County. This paper sought to estimate the proportion of women who deliver at home in West Pokot County and establish the factors associated with home delivery in the area.

\section{Material and Methods}

2.1. Study Area. West Pokot County is a poor, rural, and marginalized County with poorly developed infrastructure. 


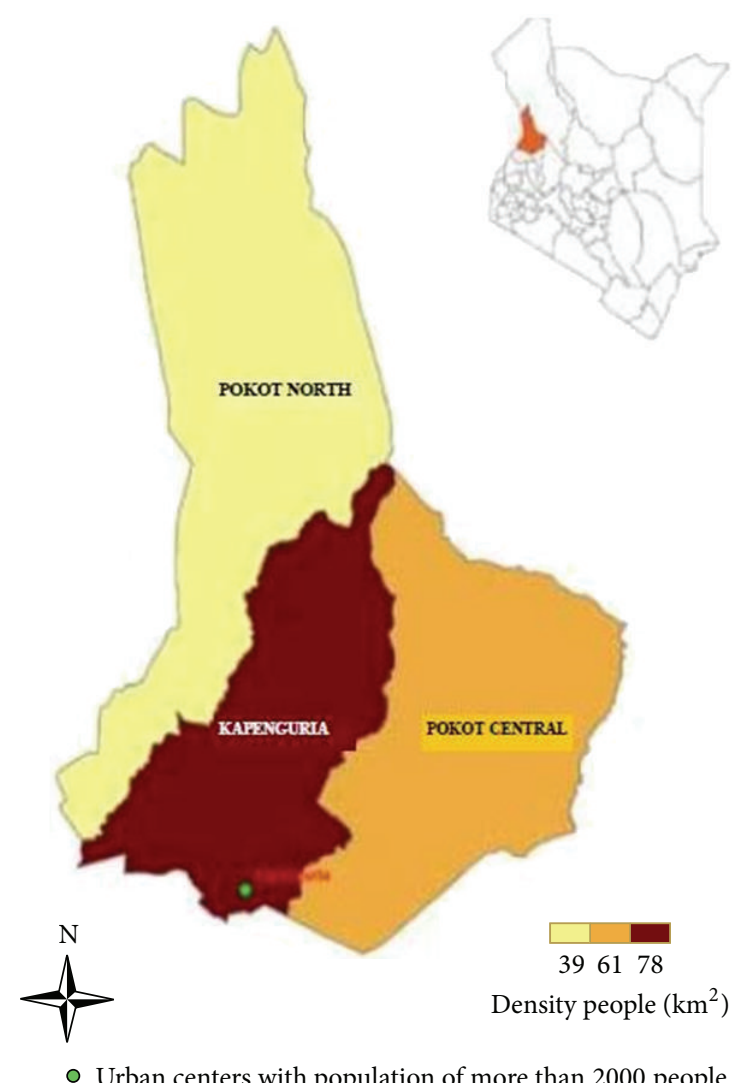

Figure 1: A map of West Pokot County.

The female genital mutilation (FGM) rate in the area is about $97 \%$, a figure that is markedly higher than the average national prevalence of $32.2 \%$. The health problems in the County are gross as manifested by the recurrent malaria episodes, ever increasing HIV/AIDS prevalence, and high maternal and neonatal mortality. The combination of harsh climatic condition, cultural practices, difficult terrain, and poor infrastructure has left the County trailing in health and development with devastating consequences on both economic, social, and health statuses of its residents. Figure 1 shows the map of West Pokot County.

2.2. Study Design and Participants. The household survey targeted all the 18,174 households in the study area between the months of April and July 2013. Participants targeted in these households were women of reproductive age who had given birth within six months prior to the study or their immediate family members in case of deceased mothers. Inclusion of underage girls was due to early marriages and pregnancies, which are too rampant in the County, and the fact that early pregnancies also contribute to significant number of pregnancy and childbirth related deaths and disability worldwide [2,5]. Of the 18,174 targeted households, 56 (8.5\%) refused to participate, leaving 18,118 households. Out of the 18,118 households, 1,679 households were located in conflict and banditry areas. These households were inaccessible to the researcher. This left 16,439 households for the survey. One thousand seven hundred and thirty-five households located in bandit prone areas were inaccessible to the interviewers due to security reasons. Only 600 mothers in the 16,439 households visited met the inclusion criteria.

2.3. Data Collection. Forty-three community health workers with a basic undergraduate degree in community health did data collection. They were trained for two days on data collection procedures and other aspects related to the study. A structured interviewer administered questionnaire was used to collect data. Deliveries that took place in a health facility were verified by GoK approved documents such as birth notification cards, birth certificates, and immunization cards. It was assumed that the birth had taken place at home in cases where the mother or families members of the deceased mother failed to produce any of these documents.

2.4. Data Management and Analysis. The study employed Statistical Package for Social Scientists (SPSS) Software version 20.0 for Windows in data analysis. Association between predictors and the place where the delivery took place was analysed by chi-square test $\left(\chi^{2}\right)$ at $95 \%$ confidence interval (CI). Factors with $P$ value $<0.05$ were considered statistically significant. These factors were entered into multivariate logistic regression model after controlling for confounding to ascertain how each influenced home delivery. Odds ratio (OR) was used to determine the extent of association. Factors analysed included maternal age and education, marital status, occupation, socioeconomic status, distance from the nearest health facility, possession of an insurance cover, and parity. Criteria used in evaluating the socioeconomic status of the mothers are reported elsewhere [6].

2.5. Ethical Consideration. The study obtained ethical approval from Mount Kenya University. It also sought written consent from all the study participants. Ethical issues (including plagiarism, informed consent, misconduct, data fabrication and/or falsification, double publication and/or submission, redundancy, etc.) have been completely observed by the author.

\section{Results}

3.1. Characteristics of the Respondents. Based on the mother's most recent births, $200(33.3 \%)$ women gave birth in a health facility while $400(66.7 \%)$ delivered at home. Sixtyfive percent $(n=390)$ of the respondents were $<20$ years, $21.7 \%$ were $20-35$ years $(n=130)$, and $13.3 \%$ were above 35 years of age $(n=80)$. In terms of the mothers level of education, $1.3 \%(n=8)$ were illiterate, $97.8 \%$ were educated $(n=587)$ up to primary level, $0.5 \%$ were up to secondary level $(n=3)$, and $0.3 \%$ were up to tertiary level $(n=2)$. Most of the women who gave birth at home were either illiterate or had basic education (86.7\%). Majority of the women interviewed were single mothers $(63.8 \% ; n=383), 114$ were married (19\%), and 103 were divorced (17.2\%). 66.7\% of women in the County were found to be giving birth at home. Table 1 shows 
TABLE 1: Sociodemographic correlates for choice of place of childbirth.

\begin{tabular}{|c|c|c|c|c|c|c|c|}
\hline \multirow{3}{*}{ Variables } & \multicolumn{4}{|c|}{ Place of delivery } & \multirow{3}{*}{ OR } & \multirow{3}{*}{$95 \% \mathrm{CI}$} & \multirow{3}{*}{$P$} \\
\hline & \multicolumn{2}{|c|}{ Facility } & \multicolumn{2}{|c|}{ Home } & & & \\
\hline & $N(200)$ & $\%$ & $N(400)$ & $\%$ & & & \\
\hline \multicolumn{8}{|l|}{ Age (in years) } \\
\hline$<20$ & 152 & 39.0 & 238 & 61.0 & $2.2 \mathrm{ref}$ & $1.5-3.2$ & $<0.001$ \\
\hline $20-35$ & 36 & 27.7 & 94 & 72.3 & 0.6 & $0.4-1.0$ & 0.02 \\
\hline$>35$ & 12 & 15.0 & 68 & 85.0 & 0.3 & $0.1-0.6$ & $<0.001$ \\
\hline \multicolumn{8}{|c|}{ Level of education } \\
\hline Illiterate & 4 & 50.0 & 4 & 50.0 & 2.0 & $0.5-8.2$ & 0.5 \\
\hline Primary & 196 & 33.4 & 391 & 66.6 & 0.5 & $0.1-2.0$ & 0.5 \\
\hline Secondary & 0 & 0.0 & 3 & 100.0 & - & & \\
\hline Tertiary & 0 & 0.0 & 2 & 100.0 & - & & \\
\hline \multicolumn{8}{|l|}{ Marital status } \\
\hline Single & 154 & 40.2 & 229 & 59.8 & $2.5 \mathrm{ref}$ & $1.7-3.7$ & $<0.001$ \\
\hline Married & 33 & 28.9 & 81 & 71.1 & 0.6 & $0.4-1.0$ & 0.03 \\
\hline Divorced & 13 & 12.6 & 90 & 87.4 & 0.2 & $0.1-0.4$ & $<0.001$ \\
\hline \multicolumn{8}{|l|}{ Occupation } \\
\hline Housewife & 52 & 70.3 & 22 & 29.7 & 6.0 & $3.5-10.3$ & $<0.001$ \\
\hline Employed & 148 & 28.1 & 378 & 71.9 & - & & \\
\hline \multicolumn{8}{|c|}{ Socioeconomic status (Sh.) } \\
\hline$<5000$ & 72 & 54.1 & 61 & 45.9 & $3.1 \mathrm{ref}$ & $2.1-4.7$ & $<0.001$ \\
\hline $5000-10000$ & 60 & 30.6 & 136 & 69.4 & 0.4 & $0.2-0.6$ & $<0.001$ \\
\hline$>10000$ & 68 & 25.1 & 203 & 74.9 & 0.3 & $0.2-0.5$ & $<0.001$ \\
\hline \multicolumn{8}{|c|}{ Distance from the nearest health facility $(\mathrm{km})$} \\
\hline$>10$ & 169 & 37.1 & 287 & 62.9 & $0.5 \mathrm{ref}$ & $0.3-0.7$ & 0.001 \\
\hline$<5$ & 21 & 29.2 & 51 & 70.8 & 0.7 & $0.4-1.2$ & 0.2 \\
\hline $5-10$ & 10 & 13.9 & 62 & 86.1 & 0.3 & $0.1-0.6$ & $<0.001$ \\
\hline \multicolumn{8}{|c|}{ Possession of a medical insurance cover } \\
\hline No & 161 & 40.7 & 235 & 59.3 & 2.9 & $1.9-4.3$ & $<0.001$ \\
\hline Yes & 39 & 19.1 & 165 & 80.9 & & & \\
\hline \multicolumn{8}{|l|}{ Parity } \\
\hline 1 & 31 & 68.9 & 14 & 31.1 & $5.1 \mathrm{ref}$ & $2.6-9.8$ & $<0.001$ \\
\hline 2 & 105 & 29.9 & 246 & 70.1 & 0.2 & $0.1-0.4$ & 0.001 \\
\hline$>3$ & 64 & 31.4 & 140 & 68.6 & 0.2 & $0.1-0.4$ & 0.001 \\
\hline
\end{tabular}

sociodemographic characteristics of the women by place of delivery.

3.2. Bivariate Analyses. Mothers aged $<20$ years were twice more likely to give birth at home compared to those aged 20-35 and $>35$ years (OR, 2.2, 95\% CI, 1.5-3.2; $P<0.001$ ). Similarly, single mothers were three times likely to deliver at home compared to their married or divorced counterparts (OR, 2.5, 95\% CI, 1.7-3.7; $P<0.001$ ) while housewives were six times more likely to deliver at home compared to those who were employed (OR, 6.0, 95\% CI, 3.5-10.3; $P<$ $0.001)$. Women of low socioeconomic status $(<$ Sh. 5000) were three times more likely to deliver at home compared to those of medium (Sh. 5000-10000) or high (Sh. >10000) socioeconomic status (OR, 3.1, 95\% CI, 2.1-4.7, $P<0.001$ ). Mothers who had no medical insurance cover were 3 times more likely to deliver at home compared to those who had none (OR, 2.9, 95\% CI, 1.9-4.3; $P<0.001$ ) while first time mothers were five times more likely to give birth at home compared to those who had two or more children (OR, 5.1, 95\% CI, 2.6-9.8; $P<0.001$ ). Level of education was comparable among women who delivered at home and at the facility $(P=0.5$ and $P=0.5$, resp.) (Table 1$)$.

3.3. Multivariate Analysis. Of the factors considered in bivariate analysis, housewives, women of socioeconomic status $<$ Sh. 5000 , and those located $>10 \mathrm{~km}$ to the nearest health facility were factors associated with giving birth at home. Compared to employed mothers, mothers who were housewives were 5 times more likely to deliver at home (OR, 4.5, 95\% CI, 2.1-9.5; $P=0.001$ ). Mothers whose socioeconomic status was $<$ Sh. 5000 were 4 times more likely to deliver at home compared to mothers who had a higher socioeconomic status (OR, 4.4, 9.5\% CI, 2.4-8.1; $P=0.001)$. Those located $>10 \mathrm{~km}$ to the nearest health facility were once more likely to give birth at home as opposed to $5-10 \mathrm{~km}$ (OR, 
TABLE 2: Multivariate analysis of predictors of place of delivery.

\begin{tabular}{|c|c|c|c|c|c|c|c|}
\hline \multirow{3}{*}{ Variables } & \multicolumn{4}{|c|}{ Place of delivery } & \multirow{3}{*}{ OR } & \multirow{3}{*}{$95 \% \mathrm{CI}$} & \multirow{3}{*}{$P$} \\
\hline & \multicolumn{2}{|c|}{ Facility } & \multicolumn{2}{|c|}{ Home } & & & \\
\hline & $N$ & $\%$ & $N$ & $\%$ & & & \\
\hline \multicolumn{8}{|c|}{$\overline{\text { Age (in years) }}$} \\
\hline$<20$ & 152 & 39.0 & 238 & 61.0 & 0.7 & $0.4-1.3$ & 0.23 \\
\hline \multicolumn{8}{|l|}{ Marital status } \\
\hline Single & 154 & 40.2 & 229 & 59.8 & 1.3 & $0.6-2.5$ & 0.5 \\
\hline \multicolumn{8}{|l|}{ Occupation } \\
\hline Housewife & 52 & 70.3 & 22 & 29.7 & 4.5 & $2.1-9.5$ & 0.001 \\
\hline \multicolumn{8}{|c|}{ Socioeconomic status (Sh.) } \\
\hline$<5000$ & 72 & 54.1 & 61 & 45.9 & 4.4 & $2.4-8.1$ & 0.001 \\
\hline \multicolumn{8}{|c|}{ Distance from the nearest health facility $(\mathrm{Km})$} \\
\hline$>10$ & 169 & 37.1 & 287 & 62.9 & $0.5 \mathrm{ref}$ & $0.3-0.7$ & 0.001 \\
\hline \multicolumn{8}{|c|}{ Possession of a medical insurance cover } \\
\hline No & 161 & 40.7 & 235 & 59.3 & 1.7 & $0.96-3.0$ & 0.07 \\
\hline \multicolumn{8}{|l|}{ Parity } \\
\hline 1 & 31 & 68.9 & 14 & 31.1 & 1.5 & $0.5-4.6$ & 0.51 \\
\hline
\end{tabular}

0.5, 9.5\% CI, 0.3-0.7; $P=0.001)$. Mothers who aged $<20(\mathrm{OR}$, $0.7,95 \% \mathrm{CI}, 0.4-1.3 ; P=0.23$ ), single mothers (OR, $1.3,95 \%$ CI, 0.6-2.5; $P=0.5$ ), lack of a medical insurance cover (OR, $1.7,95 \% \mathrm{CI}, 0.96-3.0 ; P=0.07$ ), and first time mothers (OR, $1.5,95 \% \mathrm{CI}, 0.5-4.6 ; P=0.51)$ were comparable between mothers who gave birth at facility and home (Table 2 ).

\section{Discussion}

This study has documented the percentage of women who deliver at home in West Pokot County of Kenya. It found out that $66.7 \%$ of women in the County give birth at home. This figure is $6.3 \%$ lower than the previously estimated levels of $74 \%[1,3,5]$. The increase in the number of women giving birth in the health facility could be because of various safe motherhood interventions instituted by the Government of Kenya and other stakeholders aimed at reducing maternal and child mortality rates in the County. Such interventions include but not limited to provision of free maternity services.

However, maternal deaths rate in West Pokot County is still arguably higher when compared to other similar rural areas in the country [7]. This finding reflects a huge variation in the utilization of maternal health services across the country. It also shows that many women still prefer to give birth at home than in the health facilities. This is not only a trend in Kenya but also in other developing countries $[1-3,5,8,9]$. Hence, there is a need to implement new and noble interventions that can help improve maternal health in the area. In particular, the interventions should encourage women to deliver in the health facilities. This will help support the existing interventions such as free maternal health care including maternity services $[1,3,4]$.

The study also provides an insight into some factors associated with the utilisation of maternity health services in West Pokot County. As the study depicted, most women in the study area are either illiterate or have basic education. A number of studies conducted in developing world that have linked marital status with home delivery [10, 11]. Being a housewife coupled with poor or no education, harsh climatic conditions, inadequate public utilities including healthcare services, and transport system impacts negatively on women in West Pokot County ability to access maternal services.

Most often, women who are purely housewives have limited or no access to resources and at the same time lack ability to make decision in their marital homes; they are therefore entirely compelled to rely on their mothers' inlaw perception of their pregnancy including delivery care needs [12]. Socioeconomic status is another factor that was found to influence women to home delivery. This can be attributed to the unavailability of cash for transport even in a case of free maternal services, which bias decisions towards home deliveries [13]. Lack of income is a known barrier to delivery at health facility [14-19]. This finding is in agreement with a similar finding of a study conducted in rural and marginalised community in Tanzania [20]. However, it contradicts another in Nepal, which showed that economic factors insignificantly influence place of birth [21]. These calls for simple interventions that can help empower women economically in West Pokot. For instance, women in the County should be encouraged to form Women Groups and other Self-Help Groups. Through such forums, they can help them pull resources together and exchange maternal health related information [5].

The study has also shown that distance to the nearest health facility is a factor that determines where delivery will take place, a finding that is in agreement with a similar finding in Nepal [22] and in rural Malawi [23]. Most often, pregnant women consider not seeking maternity services in health facilities located far from their home areas [24]. It is nearly impossible or difficult to do so especially when labor begins at night. Women who make such effort often fail while those with severe complications end up with pregnancy 
related mortalities or even death. The situation becomes even grimmer when means of transport such as in West Pokot County is poor or unavailable. Intervention such as "waiting homes" near health facilities to accommodate the expectant mothers located far from the nearest health facilities days before delivery day can be helpful in this regard [5].

Although it is carried out in West Pokot County, this study finding may be generalised to other remote and rural parts of the country. However, it suffers from a major limitation in that it solely relied on quantitative techniques. This calls for more studies employing both quantitative and qualitative approaches to corroborate these findings.

\section{Conclusions}

The findings of this study provide information for stakeholders responsible for maternal and child health in West Pokot County. It identified factors associated with women giving birth at home in West Pokot County. These include housewives, women of low socioeconomic status ( $<$ Sh. 5000), and situation of a health facility $>10 \mathrm{~km}$. These findings will assist in the formulation of safe motherhood initiatives to forestall the high maternal mortality in West Pokot County.

\section{Significance for Public Health}

Pregnancy and childbirth related complications contribute to a significant number of pregnancy and childbirth related deaths and disabilities in the world especially in developing countries. This paper sought to estimate the proportion of women who delivers at home in West Pokot County and establish the factors associated with home delivery in the area.

\section{Conflict of Interests}

The author declares that there is no conflict of interests.

\section{Acknowledgments}

The author would like to thank Mr. Joash O. Ogada and Mrs. Margaret A. Ogolla for funding the study. Appreciation also goes to the West Pokot County Health Management Team for their invaluable support during the study. Finally, the authors thank local administration, all research assistants, and mothers who participated in the study.

\section{References}

[1] NCAPD, "Maternal deaths on the rise in Kenya: a call to save women's lives," Policy Brief, vol. 9, pp. 1-9, 2010.

[2] UNFPA, Continental Review of Progress towards the Implementation of the Maputo Plan of Action (MPOA) on Sexual and Reproductive Health and Rights (SRHR), UNFPA/African Union Commission Liaison Office, Addis Ababa, Ethiopia, 2010.

[3] Kenya National Bureau of Statistics and ICF Macro, Kenya Demographic and Health Survey 2008-09, Kenya National Bureau of Statistics and ICF Macro, Calverton, Md, USA, 2010.

[4] Government of Kenya, Kenya Vision 2030: A Globally Competitive and Prosperous Kenya, Ministry of Planning and National
Development and the National Economic and Social Council (NESC), Nairobi, Kenya, 2007.

[5] B. Kavita, W. Rebekah, D. Rozalin et al., Partnership for Maternal and Neonatal Health-West Pokot District Child Survival and Health Program, Doctors of the World USA, 2007.

[6] D. Filmer and L. H. Pritchett, "Estimating wealth effects without expenditure data-or tears: an application to educational enrollments in states of India," Demography, vol. 38, no. 1, pp. 115-132, 2001.

[7] D. Hodgkin, "Household characteristics affecting where mothers deliver in rural Kenya," Health Economics, vol. 5, no. 4, pp. 333-340, 1996.

[8] A. N. Hazemba and S. Siziya, "Choice of place for childbirth: prevalence and correlates of utilization of health facilities in Chongwe district, Zambia," Medical Journal of Zambia, vol. 35, pp. 53-57, 2008.

[9] K. Cotter, M. Hawken, and M. Temmerman, "Low use of skilled attendant's delivery services in rural Kenya," Journal of Health, Population and Nutrition, vol. 24, no. 4, pp. 467-471, 2006.

[10] P. Y. Katung, "Socio-economic factors responsible for poor utilisation of the primary health care services in a rural community in Nigeria," Nigerian Journal of Medicine, vol. 10, no. 1, pp. 28-29, 2001.

[11] S. Yanagisawa, S. Oum, and S. Wakai, "Determinants of skilled birth attendance in rural Cambodia," Tropical Medicine and International Health, vol. 11, no. 2, pp. 238-251, 2006.

[12] B. Simkhada, M. A. Porter, and E. R. van Teijlingen, "The role of mothers-in-law in antenatal care decision-making in Nepal: a qualitative study," BMC Pregnancy and Childbirth, vol. 10, article 34, 2010.

[13] E. A. Envuladu, H. A. Agbo, S. Lassa, J. H. Kigbu, and A. I. Zoakah, "Factors determining the choice of a place of delivery among pregnant women in Russia village of Jos North, Nigeria: achieving the MDGs 4 and 5," International Journal of Medicine and Biomedical Research, vol. 2, no. 1, pp. 23-27, 2013.

[14] B. Amooti-Kaguna and F. Nuwaha, "Factors influencing choice of delivery sites in Rakai district of Uganda," Social Science and Medicine, vol. 50, no. 2, pp. 203-213, 2000.

[15] L. D’Ambruoso, M. Abbey, and J. Hussein, "Please understand when I cry out in pain: women's accounts of maternity services during labour and delivery in Ghana," BMC Public Health, vol. 5, article 140, 2005.

[16] National Bureau of Statistics \& Macro International, Tanzania Demographic Health Survey Key Findings, National Bureau of Statistics, Dares Salaam, Tanzania, ORC Macro, Calverton, Md, USA, 2005.

[17] J. Borghi, T. Ensor, A. Somanathan, C. Lissner, and A. Mills, "Mobilising financial resources for maternal health," The Lancet, vol. 368, no. 9545, pp. 1457-1465, 2006.

[18] M. Koblinsky, Z. Matthews, J. Hussein et al., "Going to scale with professional skilled care," The Lancet, vol. 368, no. 9544, pp. 1377-1386, 2006.

[19] W. R. Brieger, K. J. Luchok, E. Eng, and J. A. Earp, "Use of maternity services by pregnant women in a small Nigerian community," Health Care for Women International, vol. 15, no. 2, pp. 101-110, 1994.

[20] M. Mrisho, J. A. Schellenberg, A. K. Mushi et al., "Factors affecting home delivery in rural Tanzania," Tropical Medicine \& International Health, vol. 12, no. 7, pp. 862-872, 2007.

[21] A. Bolam, D. S. Manandhar, P. Shrestha, M. Ellis, K. Malla, and A. M. Costello, "Factors affecting home delivery in the 
Kathmandu Valley, Nepal," Health Policy and Planning, vol. 13, no. 2, pp. 152-158, 1998.

[22] S. K. Shrestha, B. Banu, K. Khanom et al., "Changing trends on the place of delivery: why do Nepali women give birth at home?" Reproductive Health, vol. 9, no. 1, article 25, 2012.

[23] T. Kulmala, Maternal health and pregnancy outcomes in rural Malawi [Ph.D. dissertation], Medical School, University of Tempere, Acta Electronica Universitatis Temperenasis 76, 2000.

[24] S. Thaddeus and D. Maine, "Too far to walk: maternal mortality in context," Social Science and Medicine, vol. 38, no. 8, pp. 10911110, 1994. 


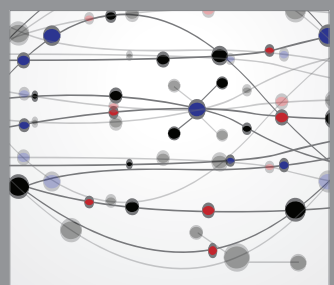

The Scientific World Journal
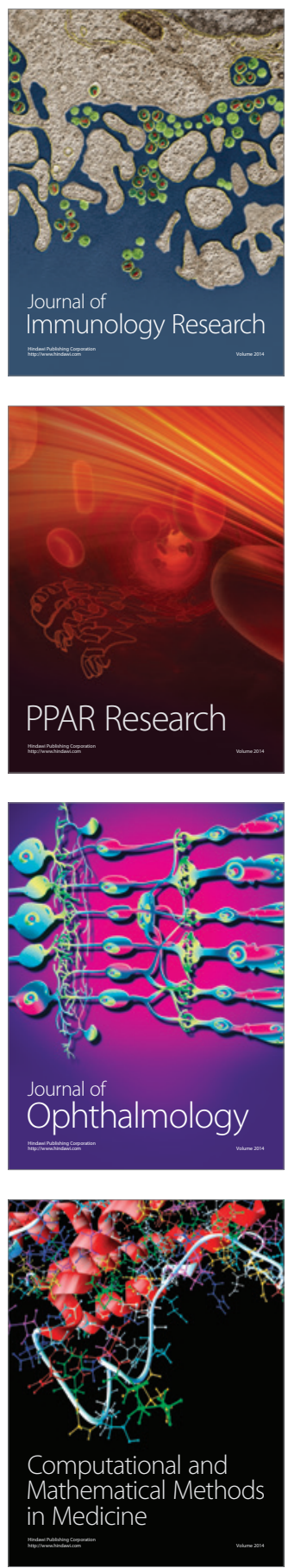

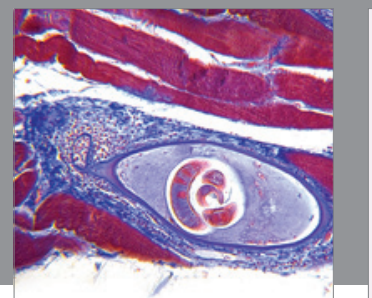

Gastroenterology

Research and Practice
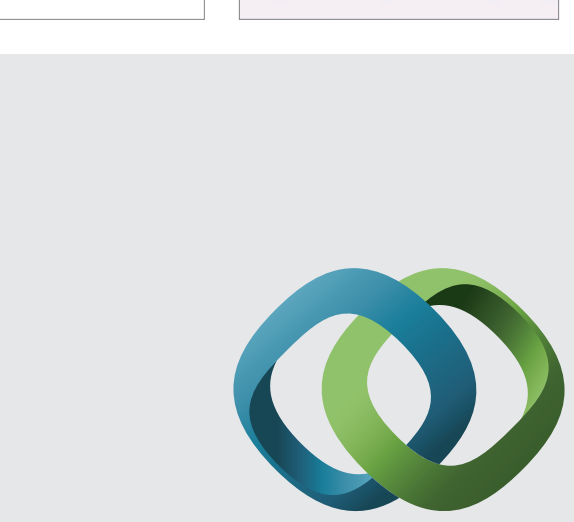

\section{Hindawi}

Submit your manuscripts at

http://www.hindawi.com
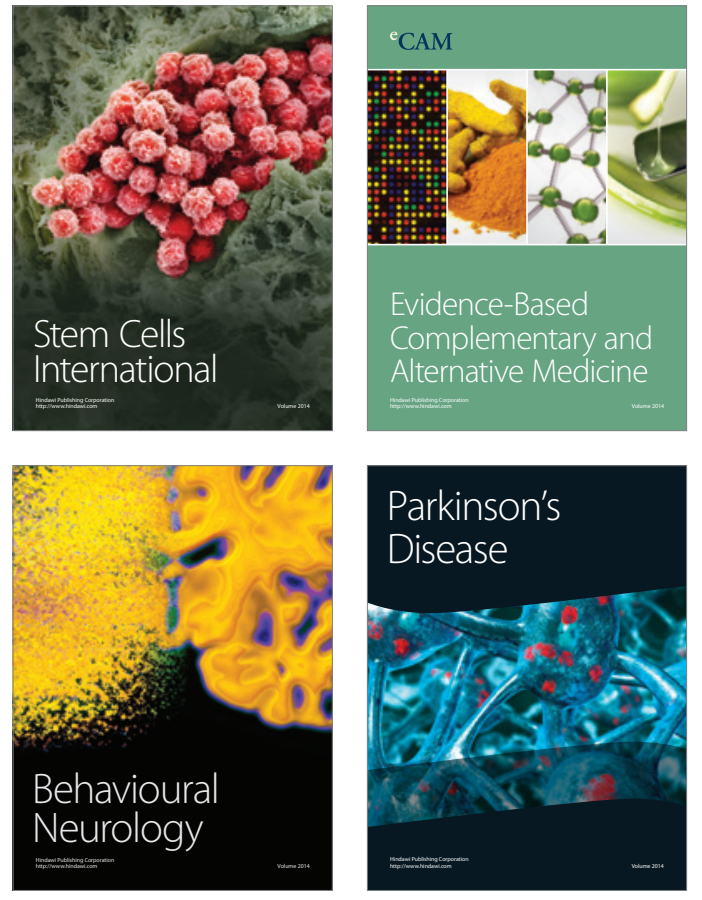
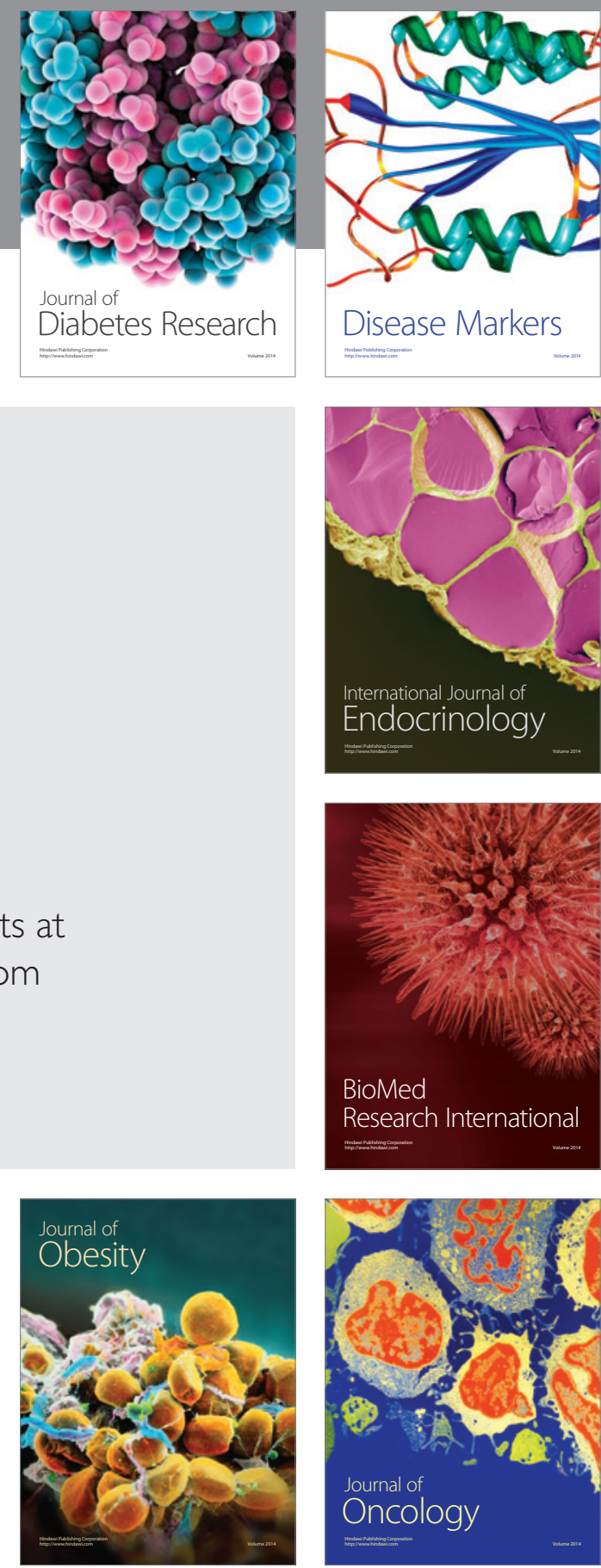

Disease Markers
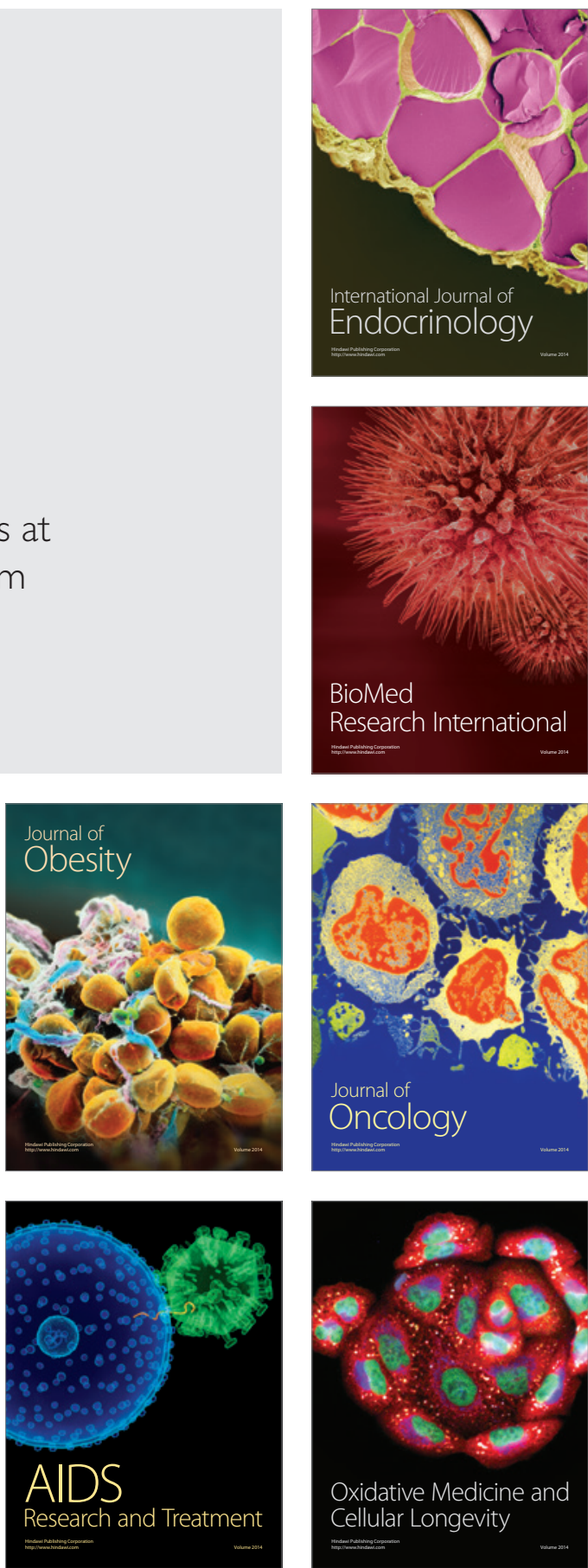